Article

\title{
Spatiotemporal Characteristic of Land Use/Land Cover Changes in the Middle and Lower Reaches of Shule River Basin Based on an Intensity Analysis
}

\author{
Fuwen Da ${ }^{1,2, *}$, Xingpeng Chen ${ }^{1,2}$ and Jinghui $\mathrm{Qi}^{3}$ \\ 1 College of Earth and Environmental Sciences, Lanzhou University, Lanzhou 730000, Gansu, China; \\ chenxp@lzu.edu.cn \\ 2 Research Institute for Circular Economy in Western China, Lanzhou University, Lanzhou 730000, China \\ 3 School of Civil Engineering and Architecture, Zhengzhou University of Aeronautics, Zhengzhou 450000, \\ Henan, China; qijh2014@lzu.edu.cn \\ * Correspondence: Fwda100@163.com; dafw13@1zu.edu.cn
}

Received: 7 January 2019; Accepted: 22 February 2019; Published: 5 March 2019

\begin{abstract}
The vegetation response to climatic factors is a hot topic in global change research. With the Support of ArcGIS and ENVI software, six sets of Landsat remote sensing images of the middle and lower reaches of the Shule River Basin were interpreted. Eight types of land use and land covers were obtained and the spatiotemporal characteristics of the land use/land cover changes (LUCCs) were analyzed using an intensity analysis to provide a basis for decision-making on the sustainable development of the basin. In the past 29 years, the area of cropland, construction land and shrubland had a net increase, while high-coverage grassland (HCG), medium-coverage grassland (MCG), low-coverage grassland (LCG), wetland and non-vegetation land all presented a net decrease. The area of artificial vegetation (cropland) presented an expanding trend and increased by $1105.56 \mathrm{~km}^{2}$ in total, while the natural vegetation (grassland, shrubland, wetland) showed a shrinking tendency and decreased by $917.69 \mathrm{~km}^{2}$. The intensity analysis revealed that the rate of LUCC in the period of 2000 2006 and 2006 2010 was relatively higher, although the rate of LUCC in other periods was much lower. The change intensities of MCG and HCG were greatest, followed by LCG, shrubland and wetland. Construction land and cropland were in third place, while non-vegetation land was in last place. The pattern of regional LUCC was generally stable except for cropland loss and the gain/loss change of other land-use/land-cover types was always in an active state. For spatial distribution, few changes were observed in the old irrigated area within the oasis. The LUCC was mainly concentrated in the oasis fringe area, natural vegetation cover area and emigrant arrangement regions.
\end{abstract}

Keywords: land use/cover change; intensity analysis; land use change intensity

\section{Introduction}

Since the mid-20th century, land use/land cover change (LUCC) research has become a popular issue in global change research and has now entered the Global Land Project (GLP) stage. In 1999, IGBP and IHDP jointly published the "Land Use/Cover Change Research Implementation Strategy," which focused on land use processes, natural and human responses to LUCC and global and regional integrated models as the research theme and emphasized LUCC. Research must be linked to sustainable development issues, such as regional land degradation, water resources and poverty [1-4].

The impact of human activities on the natural landscape is very obvious [5]. Arid and semi-arid regions are fragile and sensitive to global changes and human activities and they are the focus of global change research [6-8]. At present, some scholars have studied LUCC in the world's major arid and semi-arid regions, such as Central Asia and Africa. As the scale of cultivated land continues to expand, 
natural vegetation shows a significant degradation trend [9-12] and other reports have indicated that since the 1980s, the vegetation in the arid and semi-arid regions of the world has shown a significant "greening" situation $[13,14]$.

Through research on LUCC driving forces and driving mechanisms and the LUCC mechanisms and effects of LUCC, research models are established, and sustainable land use countermeasures are developed. The traditional LUCC research methods mainly include dynamic degree model $[15,16]$, transfer matrix [17,18], landscape pattern index [19-21] and so forth. In 2012, Professor Pontius of Clark University in the United States proposed a new method named "Intensity analysis" [22-24]. Based on the land change transfer matrix, the method analyses the intensity of local transformation from the interval level, the land level and the transformation level [25]. This method makes up for the shortcomings of the traditional LUCC analysis method, which only pays attention to the absolute quantity of change and ignores the relative quantity of change and it comprehensively considers the duration of land use change, the absolute quantity of conversion and the scale of the transferred land. At present, the theoretical system of this method is mature and although it has been widely used in foreign LUCC research [26-28], relatively few studies have applied it in China [29,30], especially for LUCC studies in the arid and semi-arid areas of China.

The Shiyang River, Heihe River and Shule River are the three inland rivers in the Hexi Corridor, all originating from the Qilian Mountains, which are supplied by meltwater and rainwater. The Shiyang River system is located in the eastern section of the Hexi Corridor. The Qianshan Mountain Area of the southern Qilian Mountains is the loess geological landscape with the piedmont alluvial fans. Dominated by gravel desert, the northern part is accompanied by denuded rocky mountains and mounds. The Tengger Desert is in the east and the Wuwei Basin in the middle. The Heihe River system is between the Dahuang Mountain and Jiayuguan, most of which is of gravel and sandy desert. Many sand dunes are mostly distributed in the northern margin. Only have a large area of oasis formed between Zhangye, Linze and Gaotai, as well as in Jiuquan area, which is an important agricultural area in Hexi. However, due to the over-exploitation of water resources in the Shiyang River and the Heihe River Basin, the ecological environment has continued to deteriorate, and the scope and extent of the damage are expanding. That has caused the widespread concern of domestic scholars Compared with the Shiyang River [31-33] and Heihe River [34-37], which are the inland rivers in the Hexi Corridor, research on the Shule River Basin is very weak [38-40]. Therefore, it is necessary to strengthen the LUCC research in this area. Based on this, this paper uses Landsat remote sensing image as the data source and applies the intensity analysis method and land use conversion intensity index to study the temporal and spatial characteristics of LUCC in the Shule River Basin in the past 29 years to provide a decision-making basis for the sustainable development of the basin.

\section{Study Area, Data and Methods}

\subsection{Overview of the StudyArea}

The Shule River is $770 \mathrm{~km}$ in length, with a total area of approximately $100,000 \mathrm{~km}^{2}$. It is located at the junction of the Qinghai-Tibet high and cold region and northwest arid and semi-arid region in China (Figure 1). The southern part of the Shule River Basin is the Altun-Qilian Mountain, which is steep and where the valleys are distributed, with many "V-shaped" gullies. The structural fissures are developed, and the erosion is strong. It is the main formation area of the Shule River runoff. In the central Hexi Corridor, the terrain is flat. After running out of Changma Fort, the Shule River is scattered on the Changma alluvial fan. It flows through above-ground and underground runoffs in both eastern and western directions, finally consumed in Dry Sea in the east and the Dunhuang West Lake in the west. The study area is located in the oasis area in the middle and lower reaches of the Shule River.The upper reaches of the Shule River are $4.41 \times 10^{4} \mathrm{~km}^{2}$, the middle and lower $6.14 \times 10^{4} \mathrm{~km}^{2}$. and it belongs to the western section of the Hexi Corridor and has a mean elevation of $1.4 \mathrm{~km}$. It is distributed in three major basins, Huahai, Yumen-Tianshi and Anxi-Dunhuang and 
along the mainstream of the Baiyang River, Petroleum River and Shule River. The Yulin River and the Danghe River are distributed from east to west. The study area is in the arid and temperate zone of Hexi and the mean annual temperature ranges from 0 to $10^{\circ} \mathrm{C}$ and the mean annual precipitation ranges from 30 to $70 \mathrm{~mm}$, and the annual mean evaporation ranges from 2400 to $3200 \mathrm{~mm}$. The growth of natural vegetation mainly depends on groundwater and the corresponding vegetation types are mainly cultivated vegetation, temperate desert and saline meadow. The "Old Silk Road" passes through this region, which also includes world cultural heritage Dunhuang Mogao Grottoes, natural wonders Mingsha Mountain and Crescent Moon Spring. In addition, the study region is also an important supporting area for the construction of the Golden Section of the "Silk Road Economic Belt" in Gansu and it includes Yumen City, Guazhou County and Dunhuang City in the administrative divisions, which are the main gathering areas for population and social and economic activities in the basin. Major industries include cultural tourism, new energy industry, equipment manufacturing, mining, coal petrochemical industry and specialty agricultural products processing industries and the basin was once an important commodity grain production base in Gansu Province. Since the 1980s, the Gansu provincial government has gradually transported more than 100,000 ecological migrants to the area, resulting in the rapid expansion of cultivated land in the area and the sharp increase in agricultural irrigation water. The contradiction between the natural ecosystem and the natural ecosystem has intensified and a series of ecological and environmental problems have emerged.

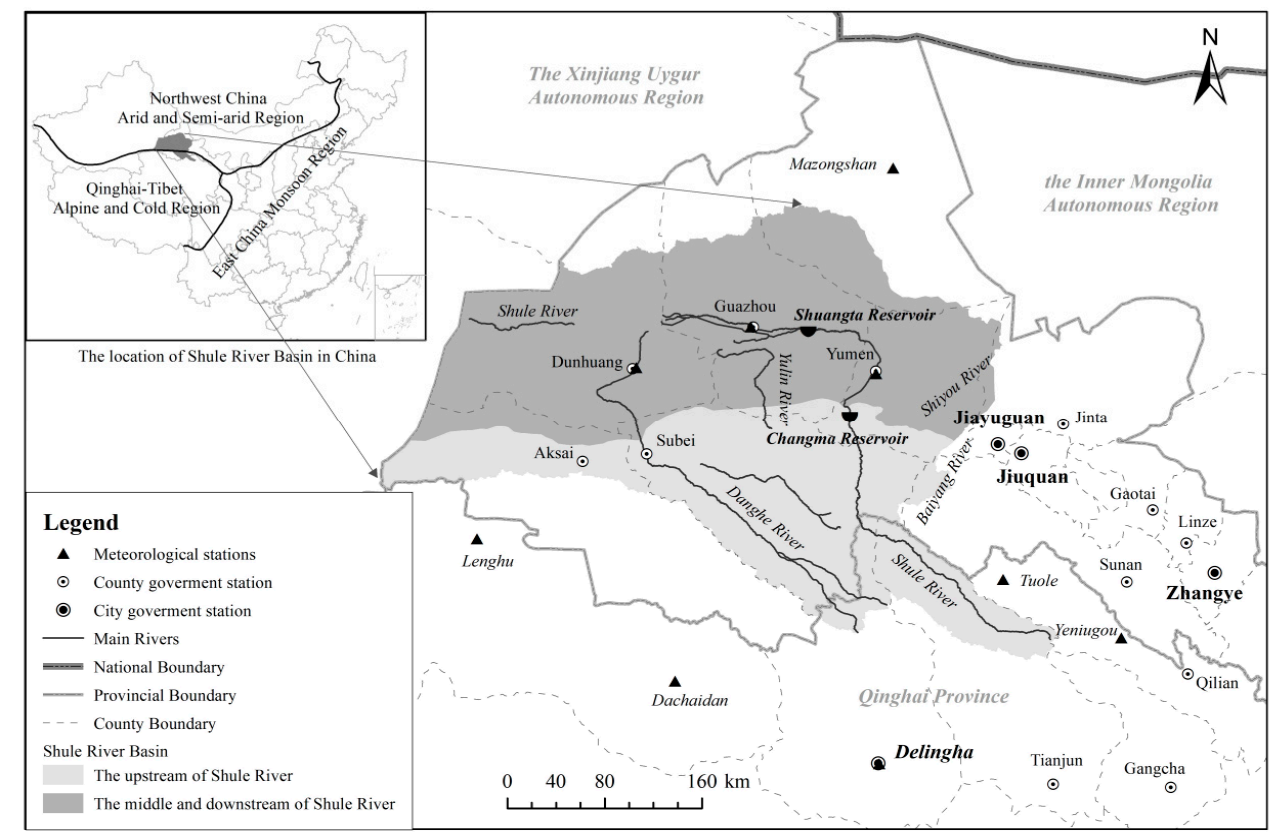

Figure 1. Location map of Shule River Basin.

\subsection{Data Source and Processing}

The data of this study are obtained from the following sources. (1) Landsat remote sensing images from 1987, 1995, 2000, 2006, 2010 and 2015 were obtained from the US Geological Survey website [41] and Institute of Remote Sensing and Digital Earth Chinese Academy of Sciences [42] and the Path/Row of remote sensing images is 135/32, 136/32, 137/32 and 138/32,During the period of 24 scenes, the imaging time was generally in July and August, which present the highest vegetation coverage and the mean cloud content was less than $10 \%$. The data quality basically met the requirements. (2) Land use data are obtained from Yumen City, Guazhou County and Dunhuang City Land and Resources Bureau. (3) Vector data and topographic maps are from the Gansu Provincial Bureau of Surveying and Mapping, the Resource and Environmental Data Cloud Platform [43] and the Cold and Arid Region Science Data Centre [44] and National Earth System Science Data Sharing Platform [45]. (4) Field observations are derived from six field surveys between 2007 and 2015. 
The remote sensing images are all radiated and geometrically corrected. Taking a 1:250,000 topographic map as reference, the quadratic polynomial model and nearest neighbor resampling method were adopted to correct each scene image geometrically and the accuracy was controlled within one pixel. Then, the corrected remote sensing images were spliced and clipped and visually interpreted in standard false-color mode. Finally, combined with field survey and land use data of the same period, the classification results were tested and the interpretation accuracy was calculated. The kappa coefficients of each period were 0.752 (1987), 0.761 (1995), 0.865 (2000), 0.861 (2006), 0.885 (2010) and 0.889 (2015), all of which met the minimum allowable discriminant accuracy of 0.7 [46]. According to the technical specifications of the ecological environment assessment issued by the Ministry of Environmental Protection in 2015 (release) and a comparison of the land use characteristics of the middle and lower reaches of the Shule River, the land use/cover types of the study area are divided into 8 categories, namely, low-coverage grassland, medium Coverage grassland, high-coverage grassland, shrubland, wetland, cultivated land, non-vegetation area and construction land. Among them, low-coverage grassland refers to the natural grassland with a coverage of 5-20\%, such as Alhagi sparsifolia and Kalidium foliatum; medium coverage grassland involves the natural grassland with a coverage of 20-50\%, such as Ephedra sinica and Achnatherum inebrians; high-coverage grassland touches on the natural grassland and improved grassland with a coverage of more than $50 \%$, such as Phragmites australis, Valerian (Achnatherum splendens) and Agropyron cristatum.

\subsection{Research Methodology}

\subsubsection{Intensity Analysis}

The interval hierarchy analysis method answers the question of how the scale and speed of land use change in different periods. Equation (1) defines the mean change intensity $S_{t}$ of a certain period of time in the research area and Equation (2) defines the mean change intensity $U$ of all periods. If $S_{t}$ is greater than $U$, it means that the land use change rate in this period is faster and vice versa [14]. A hierarchical analysis of geographical classes answers the question of how the scale and intensity of roll-in and roll-out of different geographical classes change in a specific period of time. Equations (3) and (4) define the variation intensity of a certain class in a specific period of time based on the turn in $\left(G_{t j}\right)$ and turn out $\left(L_{t i}\right)$, respectively. If $G_{t j}$ or $L_{t i}$ is greater than the mean change intensity $S_{t}$ of the time period, it means that the land class is more active and vice versa. If the land class is active or stable in all time periods, it means that the land type changes pattern. It is stable, otherwise it is not stable [20]. The transformational analytic hierarchy analysis answers the question of how the scale and intensity of conversion between a land class and other land classes change in different time periods. Equations (5) to (6) and Equations (7) to (8) focus on the transfer $\left(Q_{t m j}\right)$ inwards $\left(R_{t i n}\right)$ and the class within a specific period of time with a different conversion intensity and mean intensity $\left(W_{t n}\right.$ and $\left.V_{t m}\right)$, respectively. If $R_{t i n}$ is greater than $W_{t n}$, it means that the land class $i$ is the main source of the increase of the land area $n$. If $Q_{t m j}$ is greater than $V_{t m}$, it means that the land class $j$ is the main object of the land $m$ area. If the relationship between $R_{t i n}$ and $W_{t n}$ (or $Q_{t m j}$ and $V_{t m}$ ) has not changed in all time periods, it indicates that the change pattern of the transfer of the land class is stable [20].

$$
\begin{gathered}
\mathrm{S}_{t}=\frac{\left\{\sum_{\mathrm{j}=1}^{J}\left[\left(\sum_{i=1}^{J} C_{t i j}\right)-C_{t i j}\right]\right\} /\left[\sum_{j=1}^{J}\left(\sum_{i=1}^{J} C_{t i j}\right)\right]}{Y_{t+1}-Y_{t}} \times 100 \% \\
\mathrm{U}=\frac{\sum_{t}^{T-1}\left\{\sum_{j=1}^{J}\left[\left(\sum_{i=1}^{J} C_{t i j}\right)-C_{t j j}\right]\right\} /\left[\sum_{j=1}^{J}\left(\sum_{i=1}^{J} C_{t i j}\right)\right]}{Y_{T}-Y_{1}} \times 100 \% \\
G_{t j}=\frac{\left[\left(\sum_{i=1}^{J} C_{t i j}\right)-C_{t j j}\right] /\left(Y_{t+1}-Y_{t}\right)}{\sum_{i=1}^{J} C_{t i j}} \times 100 \%
\end{gathered}
$$




$$
\begin{gathered}
L_{t i}=\frac{\left[\left(\sum_{j=1}^{J} C_{t i j}\right)-C_{t i i}\right] /\left(Y_{t+1}-Y_{t}\right)}{\sum_{j=1}^{J} C_{t i j}} \times 100 \% \\
\mathrm{R}_{t i n}=\frac{C_{t i n} /\left(Y_{t+1}-Y_{t}\right)}{\sum_{j=1}^{J} C_{t i j}} \times 100 \% \\
\mathrm{~W}_{t n}=\frac{\left[\left(\sum_{i=1}^{J} C_{t i n}\right)-C_{t n n}\right] /\left(Y_{t+1}-Y_{t}\right)}{\sum_{j=1}^{J}\left[\left(\sum_{i=1}^{J} C_{t i j}\right)-C_{t n j}\right]} \times 100 \% \\
Q_{t m j}=\frac{C_{t m j} /\left(Y_{t+1}-Y_{t}\right)}{\sum_{i=1}^{J} C_{t i j}} \times 100 \% \\
\mathrm{~V}_{t m}=\frac{\left[\left(\sum_{j=1}^{J} C_{t m j}\right)-C_{t m m}\right] /\left(Y_{t+1}-Y_{t}\right)}{\sum_{i=1}^{J}\left[\left(\sum_{j=1}^{J} C_{t i j}\right)-C_{t i m}\right]} \times 100 \%
\end{gathered}
$$

In Equations (1)-(8), $J$ is the total number of ground classes; $i$ is a certain ground class at the starting point of a specific period of time; $j$ is a certain ground class at the end point of a specific period of time; $m$ is some kind of ground class where the area is transferred out; $n$ is some kind of ground class where the area increases; $T$ is the total number of time points; $t$ is the beginning time of the period $\left[Y_{t}, Y_{t+1}\right]$ and the value range of $t$ is from 1 to $T-1 ; Y_{t}$ is the year in which $t$ time point is located; $C_{t i j}$ is the area transformed from inland class $i$ to terrestrial class $j$ in the period of $\left[Y_{t}, Y_{t+1}\right] ; S_{t}$ is the annual change intensity of $\left[Y_{t}, Y_{t+1}\right]$; $U$ is the annual mean intensity of change in all time periods; $G_{t j}$ is the annual mean change intensity of other land classes into the land class $j$ during the $\left[Y_{t}, Y_{t+1}\right]$ period; $L_{t i}$ is the land class $i$ direction in the $\left[Y_{t}, Y_{t+1}\right]$ period The annual mean change intensity of other land classes; $R_{t i n}$ is the annual mean conversion intensity of the land class $i$ to the land class $j$ in the $\left[Y_{t}, Y_{t+1}\right]$ period, where $I \neq n ; W_{t n}$ is $\left[Y_{t}, Y_{t+1}\right]$ The annual mean conversion strength of the non- $n$ class to the ground class $n ; Q_{t m j}$ is the annual mean conversion strength of the land class $m$ to the land class $j$ during the $\left[Y_{t}, Y_{t+1}\right]$ period, where $j \neq m$; and $V_{t m}$ is $\left[Y_{t}, Y_{t+1}\right]$, which is the mean strength of the class $m$ to other non- $m$ land classes.

\subsubsection{Land Use Conversion Intensity (LCI)}

$$
L C I=\frac{S_{\text {change }}}{S_{\text {grid }} \times n} \times 100 \%
$$

where $S_{\text {grid }}$ is the area of grid. In this paper, $1 \times 1 \mathrm{~km}$ grid is selected, $S_{\text {change }}$ is the area of land use type changes within the grid and $n$ is the number of years between research periods. The index can spatialize the difference of land use conversion intensity and reveal the spatial characteristics of land use change.

\section{Results and Discussion}

The remote sensing interpretation and analysis results for the land use/cover types in the middle and lower reaches of Shule River from 1987 to 2015 are shown in Table 1. From the perspective of the change of net area, cropland and construction land show a state of continuous and rapid growth, with the growth rate reaching $95.12 \%$ and $220.99 \%$, respectively. Grassland area showed a net decrease trend, with the decreases of high-, medium- and low-coverage grasslands at $-2.19 \%,-21.26 \%$ and $-20.34 \%$, respectively. The area of shrubland increased by $49.35 \%$. The area of wetland and non-vegetation area decreased by $-12.27 \%$ and $-1.41 \%$, respectively. With the continuous increase of artificial vegetation area (cropland), natural vegetation (grassland, shrubland and aquatic wetland) shows a net decrease trend and the total natural vegetation area in the study period is reduced by $917.69 \mathrm{~km}^{2}$, with a decrease of $-15.65 \%$. 
Table 1. Area change $\left(\mathrm{km}^{2}\right)$ and variation range (\%) of different regions in the middle and lower reaches of the Shule River.

\begin{tabular}{|c|c|c|c|c|c|c|c|c|c|}
\hline \multicolumn{2}{|c|}{ Research Period } & \multirow{3}{*}{$\begin{array}{c}\text { LCG } \\
-5.55 \\
-0.15\end{array}$} & \multirow{2}{*}{$\begin{array}{c}\text { MCG } \\
-126.21\end{array}$} & \multirow{2}{*}{$\begin{array}{c}\text { HCG } \\
20.91\end{array}$} & \multirow{2}{*}{$\begin{array}{c}\text { Shrub-land } \\
-9.85\end{array}$} & \multirow{2}{*}{$\begin{array}{c}\text { Wetland } \\
-67.21\end{array}$} & \multirow{2}{*}{$\begin{array}{c}\text { Cropland } \\
105.31\end{array}$} & \multirow{2}{*}{$\begin{array}{c}\text { Non-vegetation } \\
68.47\end{array}$} & \multirow{2}{*}{$\begin{array}{c}\text { Construction Land } \\
14.12\end{array}$} \\
\hline & Area change & & & & & & & & \\
\hline $1987 \sim 1995$ & variation range & & -11.34 & 4.32 & -4.23 & -15.32 & 9.06 & 0.30 & 23.03 \\
\hline \multirow{2}{*}{ 1995 2000 } & Area change & -114.34 & -98.13 & -54.01 & 4.61 & -14.03 & 181.08 & 77.75 & 17.02 \\
\hline & variation range & -3.18 & -9.95 & -10.70 & 2.06 & -3.78 & 14.29 & 0.34 & 22.55 \\
\hline \multirow{2}{*}{ 2000 2006 } & Area change & -446.15 & 20.82 & -69.55 & 22.26 & -56.40 & 434.93 & 65.58 & 28.50 \\
\hline & variation range & -12.83 & 2.34 & -15.43 & 9.76 & -15.78 & 30.02 & 0.28 & 30.83 \\
\hline \multirow{2}{*}{ 2006 2010 } & Area change & -238.57 & 20.47 & 69.93 & 21.22 & -16.66 & 256.52 & -146.41 & 33.55 \\
\hline & variation range & -7.87 & 2.25 & 18.35 & 8.48 & -5.53 & 13.62 & -0.63 & 27.74 \\
\hline \multirow{2}{*}{ 2010 2015 } & Area change & 72.82 & -53.51 & 22.14 & 76.83 & 100.46 & 127.72 & -388.80 & 42.33 \\
\hline & variation range & 2.61 & -5.76 & 4.91 & 28.31 & 35.33 & 5.97 & -1.69 & 27.40 \\
\hline \multirow{2}{*}{ 1987 2015 } & Area change & -731.78 & -236.56 & -10.59 & 115.07 & -53.83 & 1105.56 & -323.40 & 135.53 \\
\hline & variation range & -20.34 & -21.26 & -2.19 & 49.35 & -12.27 & 95.12 & -1.41 & 220.99 \\
\hline
\end{tabular}




\subsection{Interval Hierarchy Analysis}

Based on the transfer matrix of land use change in five periods and Equations (1) to (2), the total amount of land use change in each period, mean annual change intensity $\left(S_{t}\right)$ and mean change intensity $(U)$ in all periods can be obtained as shown in Figure 2. In terms of the total amount of change, the land use changes during the three periods from 2000 to 2006, 2006 to 2010 and 1987 to 1995 were relatively strong and the changes in other periods were small. In terms of annual mean intensity, $S_{t}$ presented the lowest value from 1987 to 1995, increased sequentially and reached the highest value $\left(S_{t}=2.17 \%\right)$ during the period from 2006 to 2010 and then fell to $1.12 \%$ during the period from 2010 to 2015.From the relationship between $S_{t}$ and $U$, only the St value of 2000 2006 and 2006 2010 was greater than the mean change intensity $(U=1.32 \%)$, indicating that the land changes rapidly during the two periods and the land change is slower in other periods.

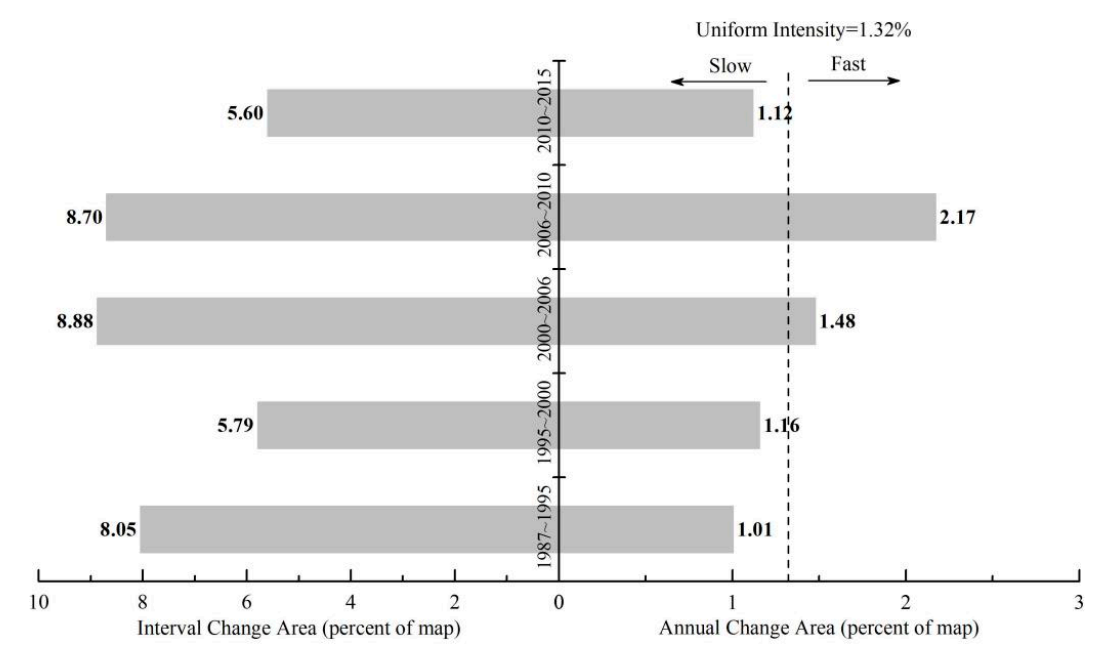

Figure 2. Interval analytic hierarchy analysis of land use change in the middle and lower reaches of the Shule River.

During the period from 1987 to 1995, St was significantly smaller than the $U$ value, indicating that the large amount of land use change during this period was mainly due to the long time span of the period. The period from 2000 to 2006 was the key period for the implementation of the "Shule River Basin Agricultural Irrigation and Resettlement Comprehensive Development Project." The migration of a large number of agricultural immigrants set off a large-scale agricultural development frenzy and accelerated the transformation of regional land use patterns. Shortly after the completion of the Shule River immigration project from 2006 to 2010, many follow-up projects were still ongoing. Later, Gansu Province implemented the resettlement project in the Jiudianxia Reservoir Area in the region, which led to the most severe land use change in the region.

\subsection{Land Class Hierarchy Analysis}

Based on the land change transfer matrix and Equations (3)-(4), the annual mean change area and annual mean change intensity $\left(G_{t j}\right.$ and $\left.L_{t j}\right)$ of each class in each period and the mean change intensity $\left(S_{t}\right)$ in the interval are obtained (Figures 3 and 4 ). The greatest mean annual change area was grassland with low coverage at above $100 \mathrm{~km}^{2}$. In particular, during the period from 2000 to 2010, the change increases sharply and reached a peak $\left(>200 \mathrm{~km}^{2}\right)$ in the period from 2006 to 2010 . The change scale of medium-coverage grassland was the same as that of non-vegetated area, ranking the second place. Before 2006, the area of non-vegetated areas was slightly larger than that of non-vegetated areas, thus showing a slight expansion trend and smaller than that of non-vegetated areas, thus showing a contraction trend. The scales of transition in and out of medium-coverage grassland were generally consistent and an increase or decrease in each other was observed, indicating that the local class is in a 
state of dynamic equilibrium. The changing scale of high-coverage grassland and cropland ranks third, among which the transfer scale of high-coverage is consistent while the transfer scale of cultivated land is obviously greater, especially from 2000 to 2010, indicating the rapid expansion of cultivated land. Shrubland and aquatic wetlands ranked the fourth in terms of change. Before 2010, their transfer amount and transfer scale were the same and the transfer volume was significantly larger, reflecting their expansion characteristics. The scale of change of construction land was the smallest and presented mean annual change of less than $10 \mathrm{~km}^{2}$ and this trend increased, especially after 2006.

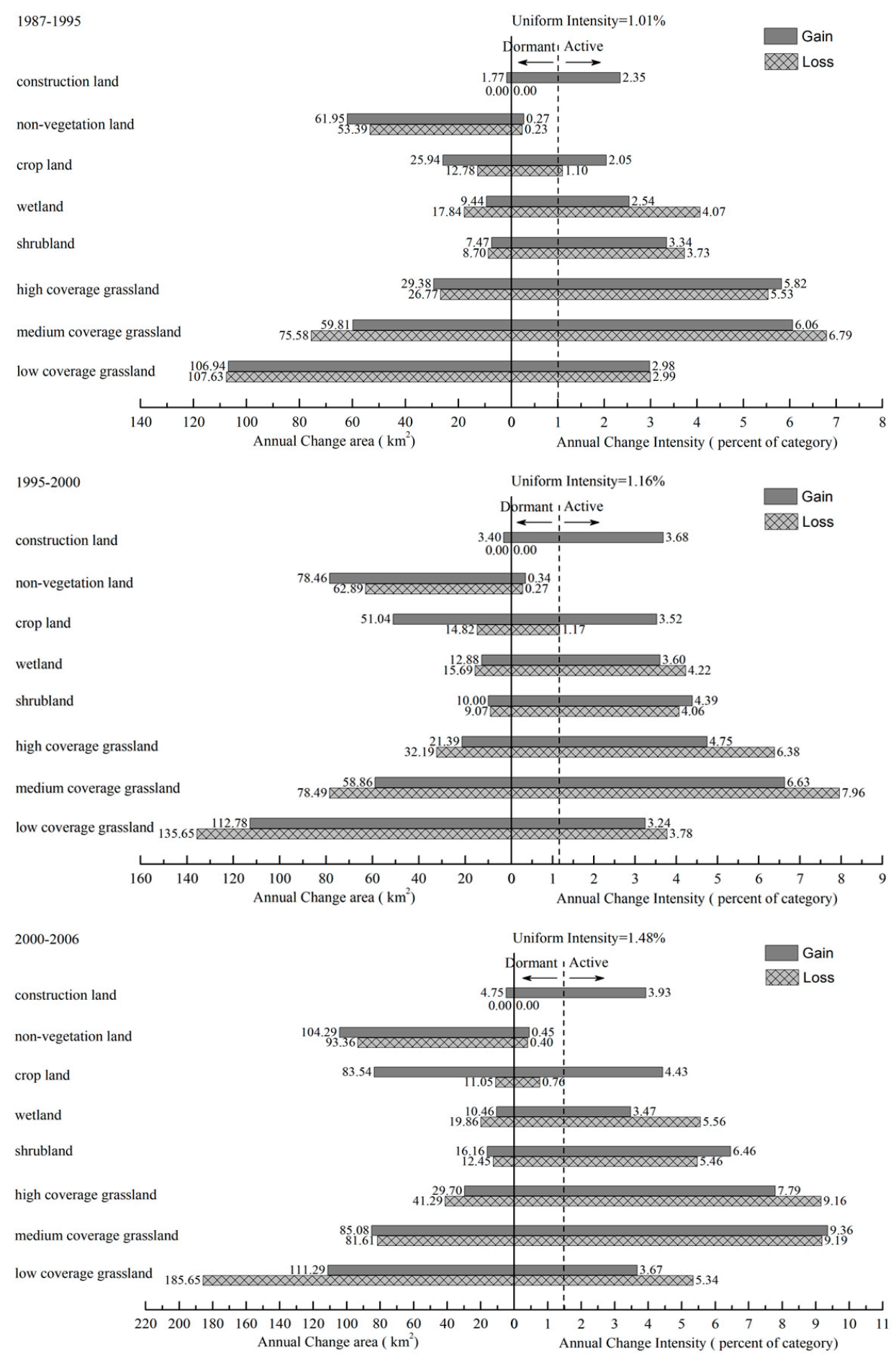

Figure 3. Analysis of land use hierarchy in the middle and lower reaches of the Shule River from 1987 to 2015 (I). 


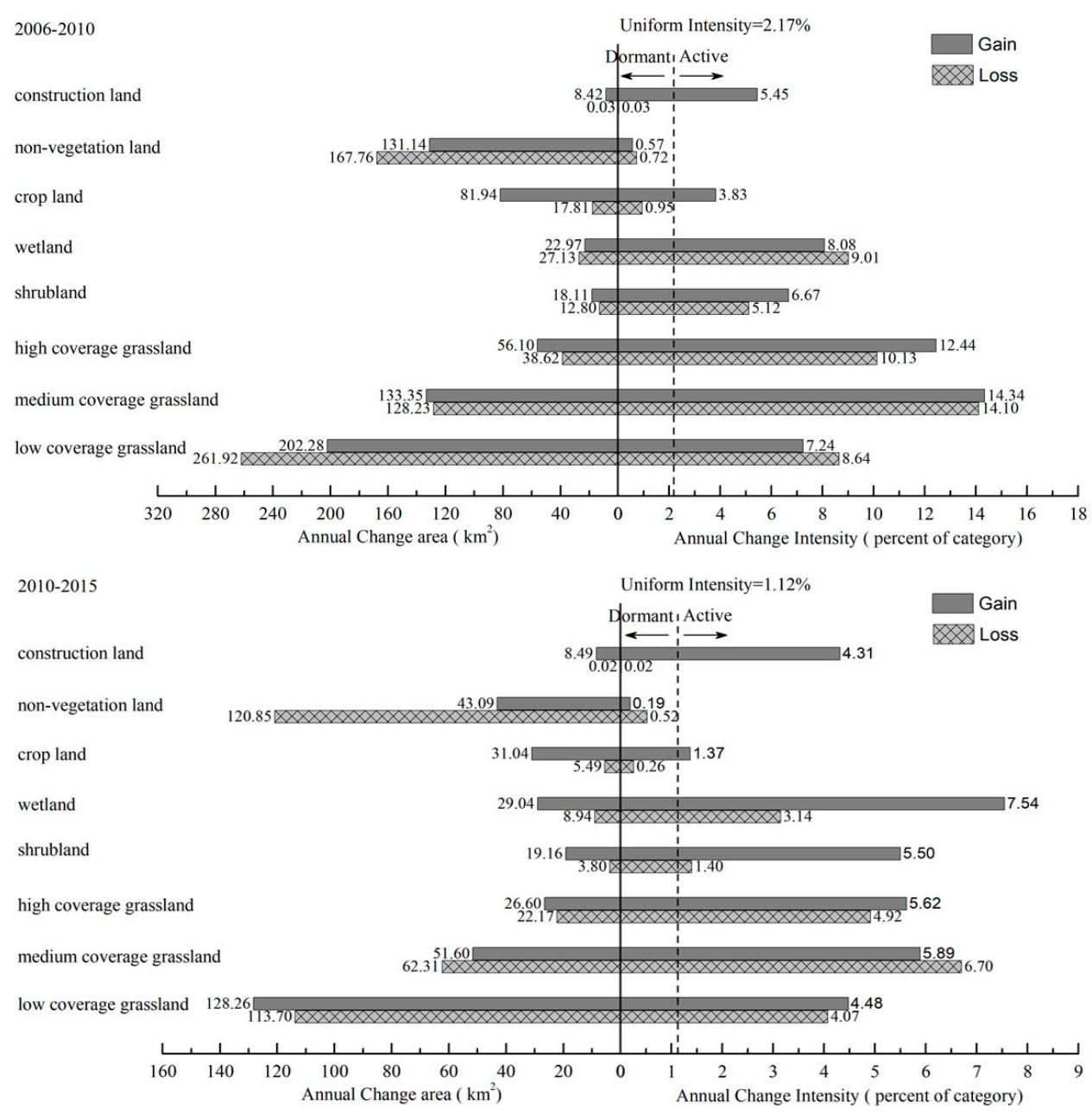

Figure 4. Analysis of land use hierarchy in the middle and lower reaches of the Shule River from 1987 to 2015 (II).

In terms of change intensity, medium- and high-coverage grassland ranked first, with higher transfer-in and transfer-out intensity and little difference in transfer-in and transfer-out intensity. The conversion intensity of low-coverage grassland, shrubland and wetland ranked second and before 2010, little difference was observed but then the transfer intensity of wetland and shrubland suddenly increased and the strength of the transfer significantly reduced, thus reflecting a strong increasing trend. The conversion intensity of construction land and cultivated land was in third place and its transfer intensity was significantly greater an increasing, thus showing a strong growth momentum. The intensity of cultivated land transfer peaked from 2000 to $2006\left(G_{t j}=4.43\right)$. The transfer intensity of construction land reached its peak value during the period from 2006 to $2010\left(G_{t j}=5.45\right)$, which reflects that the immigration climax of 2000 2010 not only brought about the rapid expansion of cultivated land area but also caused the scale of urban and rural construction to expand rapidly. The annual mean intensity of the non-vegetation area was always small, the $G_{t j}$ and $L_{\mathrm{tj}}$ values were all below $1 \%$ and the difference was almost the same. Although the absolute variation was large, the land type change was relatively stable compared to its own large scale.

With respect to the mean change in intensity $\left(S_{t}\right)$ in locations without vegetation transfer, the intensity of the transfer of construction land was always on the left of the $S_{t}$ line in Figure 3, indicating that the conversion is always in a stable state. Before 2000, the $S_{t}$ for arable land was lower, indicating a change of cropland caused by the conversion to other land uses and cropland continued to decline. Other land types were always on the right side of the St line in Figures 3 and 4, thus indicating that they are always active. Overall, from 1987 to 2015, except for cultivated land, fundamental changes were not observed in the land use pattern of the Shule River basin. 


\subsection{Transformation Hierarchy Analysis}

Based on the land change transfer matrix and Equations (5)-(8), the mean annual transfer area, annual mean transfer intensity $\left(R_{t i n}\right)$ and mean transfer of other land types into a certain land type are obtained. The strength $\left(W_{t n}\right)$, mean annual transfer area, annual mean transfer intensity $\left(Q_{t m j}\right)$ and mean transfer strength $\left(V_{t m}\right)$ of a certain land transfer to other land types are also obtained. Due to the large number of land types, the different types are impossible to draw one by one. Therefore, this paper selects cultivated land as a case for detailed graphical analysis (Figure 5) and the analyses of other land type conversions analysis are not presented.

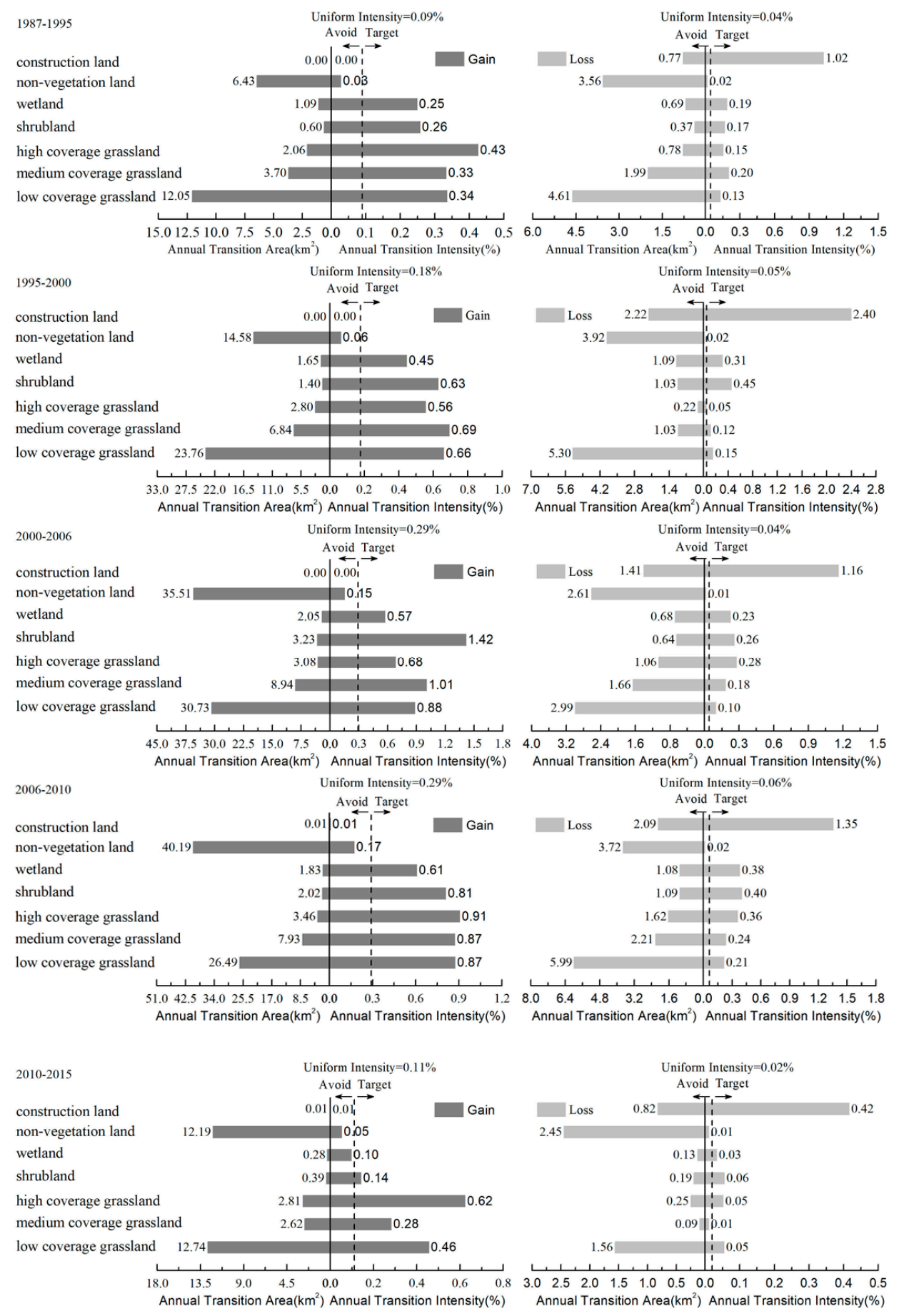

Figure 5. Analysis of the conversion level of cultivated land change in the middle and lower reaches of the Shule River from 1987 to 2015. 
The main source of increased cultivated land is the transfer of low-coverage grassland and non-vegetation area. The contribution of medium- and high-coverage grassland ranked second, shrubland and wetland ranked third and construction land made almost no contribution. The mean annual transfer intensity $R_{\text {tin }}$ values of low, medium- and high-coverage grassland and shrubland were always on the right side of the $W_{t}$ line, indicating that they are a systematic transfer source of increased cultivated land. Wetlands were a systematic source of increased cropland before 2010 and later turned into non-systematic sources. The $R_{\text {tin }}$ value of non-vegetation area and construction land is always on the left side of the $W_{t}$ line, indicating that neither of them is the main contributor to the increase of cultivated land. Although the absolute transfer amount of cultivated land without vegetation area is relatively large, it is more due to the large size of the area in the study area. The mean annual transfer area is low-coverage grassland and the non-vegetation area, although the intensity analysis shows that the cultivated land is systematically transferred to construction land. From the mean turn-in and turn-out intensity changes in each period, the $W_{t n}$ value gradually increased from $0.09 \%$ in the period of $1987-1995$ to $0.29 \%$ in the period of $2006-2010$ and then decreased to $0.11 \%$ (2010-2015 period) and the amount of change in the $V_{t m}$ value is not large at between $0.02 \%$ and $0.06 \%$, indicating that the conversion of cultivated land is the main aspect and has obvious phase characteristics between 2000 and 2010.

In terms of annual mean transfer and transfer area, the main sources of low-coverage grassland increase are medium-coverage grassland and non-vegetation area and the transfer objects are mainly medium-coverage grassland, non-vegetation area and cultivated land. From the perspective of annual mean transfer and transfer intensity, medium- and high-coverage grassland and wetland are the main sources of stable transfer. Medium- and high-coverage grassland, shrubland and cultivated land are the main transfer objects. It is worth noting that the shrubland has not been a source since 2010 and construction land has become its main target for export from 2000 to 2010. Thus, low-coverage grassland is transferred out. The pattern changed from 1987 to 2015, showing an unsteady characteristic.

For medium-coverage grassland, the results based on annual mean change area and annual mean conversion intensity are consistent. The main sources of transfer and transfer are high- and low-coverage grassland and shrubland and non-vegetation area and construction land have not been covered. The main target of grassland conversion, cultivated land and waters wetland has changed in whether it becomes the source and transfer object of medium coverage grassland.

In terms of absolute variation, the main sources of transfer and high-coverage grassland are medium- and low-coverage grassland but the intensity analysis shows that the main sources of transfer and the transfer target are medium-coverage grassland, shrubland, wetlands. Non-vegetation areas and construction land have not been the object of conversion and cultivated land is not the source of its transfer but it is its systematic transfer object.

Based on the absolute quantity change and intensity analysis, the sources of shrubland and transfer objects are high-, medium- and low-coverage grassland. Non-vegetation area and construction land are not the object of conversion. Wetland and cultivated land present a dynamic change relationship.

The main transfer sources and transfer objects of wetland annual mean conversion areas are high-, medium- and low-coverage grassland and non-vegetation areas, although from the perspective of annual mean conversion intensity, the transfer source and transfer target are mainly high-, mediumand low-coverage grassland, excluding vegetation free areas. The results of the intensity analysis show that non-vegetation area and construction land are not the conversion objects of wetland. The relationship between shrubland and cultivated land is changing. The relationship between $R_{\text {tin }}$ and $W_{t}$ is inconsistent at different time periods.

In terms of the scale of transfer, the most important source of increase in non-vegetation areas is low-coverage grassland. Although other land types have also been converted to non-vegetation areas, the conversion is small and the main target of non-vegetation areas is low-coverage grassland and cultivated land. The results of intensity analysis show that the source of non-vegetation area is only low-coverage grassland and water-wet wetland and the conversion intensity of other land types 
is less than the mean transfer intensity, while the stable transfer-out object without vegetation area has only low coverage. Whether grassland and other land types are in dynamic change with their transfer objects, the annual mean transfer area of cultivated land is relatively large and the annual mean transfer intensity is not always greater than the mean transfer strength.

The change in construction land is mainly reflected in the transfer of other land types to it and its turnover is negligible. In terms of absolute quantity, the main source of construction land increase is non-vegetation area, cultivated land and low-coverage grassland but the intensity analysis shows that the systemic transfer source is only cultivated land. Although the absolute transfer amount of the non-vegetation area is very large, due to its large area base, its annual mean intensity of conversion to construction land is less than the mean conversion intensity.

\subsection{Spatial Characteristics of Land Use/Cover Change}

\subsubsection{Spatial Distribution of Overall Land Use/Cover Change in The Region}

Land use conversion intensity index (LCI) is used to analyze the spatial distribution of the intensity of land use change.The larger the LCI value, the more severe the land conversion. First, the six stages of land use vector data are rasterized and then each two map algebra operations, namely, the initial stage of Raster early $\times 10+$ Raster $_{\text {late, }}$ to obtain the land use conversion map (LCM) of five time periods and the changing part is uniformly assigned as 1 and the unchanged part is assigned as 0 .Then, a $1 \times 1 \mathrm{~km}$ grid covering the study area is established and the area of the change part in each grid is counted. The LCI value of each grid is calculated according to Equation (9) and the land use conversion intensity of five periods can be obtained (Figure 6a-e). For the cumulative land use conversion intensity index, including all time periods, the LCM of the five time periods can be added to the map algebra to obtain the comprehensive land use conversion map. Pixel value changes between 0 and 5 indicate that the land use type changed 0 to 5 times. The areas with a value of $0 \sim 5$ in each $1 \times 1 \mathrm{~km}$ grid are counted and the weighted sum is used as the weight to obtain the total area of the land use type in all the time periods of the pixel. According to Equation (9), the LCI value of each grid is calculated to obtain the cumulative land use conversion intensity index map for all time periods (Figure 6f).

From the perspective of a single study period (Table 2), the LCI values were higher during the 2000 2006 and 2006 2010 periods and the medium-to-high conversion area accounted for more than $11 \%$ of the total area of the study area, especially during the period of 2006-2010, which was as high as $15.68 \%$, whereas it was approximately $8 \%$ in other time periods. For all the periods from 1987 to 2015, the proportion of land use change was as high as $38.18 \%$ and the medium-to-high conversion ratio exceeded $10 \%$, indicating that land use in the study area has changed drastically in the past 28 years.

Table 2. Proportion of land use conversion intensity at different periods in the middle and lower reaches of the Shule River (\%).

\begin{tabular}{|c|c|c|c|c|}
\hline Years & $(\mathrm{LCI}=0)$ & $(0<\mathrm{LCI} \leq 5)$ & $(5<\mathrm{LCI} \leq 10)$ & $(\mathrm{LCI}>10)$ \\
\hline 1987 1995 & 68.10 & 24.70 & 5.96 & 1.24 \\
\hline 1995 2000 & 74.96 & 16.32 & 5.77 & 2.94 \\
\hline 2000 2006 & 68.96 & 19.57 & 7.04 & 4.43 \\
\hline 2006 2010 & 67.44 & 16.89 & 7.62 & 8.06 \\
\hline 2010 2015 & 79.23 & 12.31 & 4.72 & 3.74 \\
\hline 1987 2015 & 61.82 & 27.74 & 9.78 & 0.67 \\
\hline
\end{tabular}

In terms of spatial distribution, although the land use conversion intensity varies from time to time, its spatial distribution is consistent. The old farming areas in the oasis have changed little and the conversion areas are mainly concentrated around the oasis, natural vegetation coverage areas and resettlement sites. Specifically, they are mainly distributed in Beihu Wetland, Donghu Wetland, Dunhuang West Lake Wetland in the north of Danghe Irrigation District, Anxi Extreme Drought Desert 
Nature Reserve in the northern part of Yulin River Irrigation District, Liudun Township Resettlement Site in Changma Irrigation District and Huahai Irrigation District Immigrants. Place around the resettlement site. In particular, the Beihu Wetland, the East Lake Wetland and the West Lake Wetland, which are located in the Dunhuang City at the end of the Shule River, have the highest land use conversion intensity, which indicates the sensitivity of land use/cover type change in the downstream of the inland river basin in the arid region.
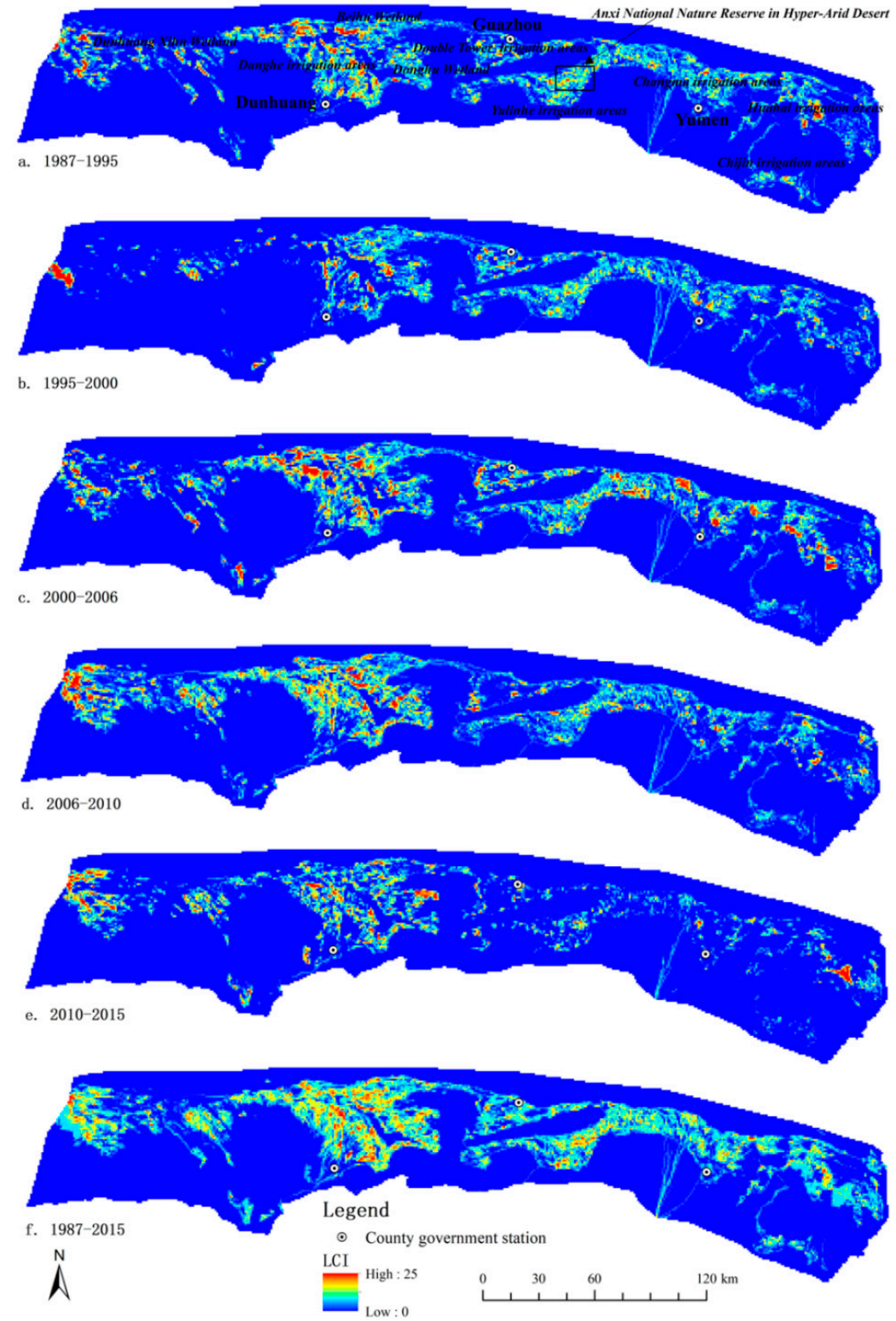

Figure 6. Spatial distribution map of land use conversion intensity at different periods in the middle and lower reaches of the Shule River.

\subsubsection{Spatial Distribution of Changes in Different Land Use/Cover Types}

The implementation of the Shule River Agricultural Irrigation and Resettlement Project occurred from 1996 to 2006. Therefore, this paper selects three typical time periods from 1987 to 1995 before implementation and from 1995 to 2006 and from 2006 to 2015 after implementation. The spatial distribution characteristics of the class changes are analyzed. Using ArcGIS software (10.2, Esri, Redlands, California) the land use classification results of two different time periods are superimposed and analyzed and the spatial distribution map of mutual conversion between different land use modes 
can be obtained. To highlight the spatial distribution information of the main land use change in the region, we combine low-coverage grassland, medium-coverage grassland and high-coverage grassland into grassland and merge the transformation modes with a change area of less than $25 \mathrm{~km}^{2}$ into other change types. The changed parts are collectively referred to as the unaltered areas, that is, the simplified LUCC profile is obtained (Figure 7).
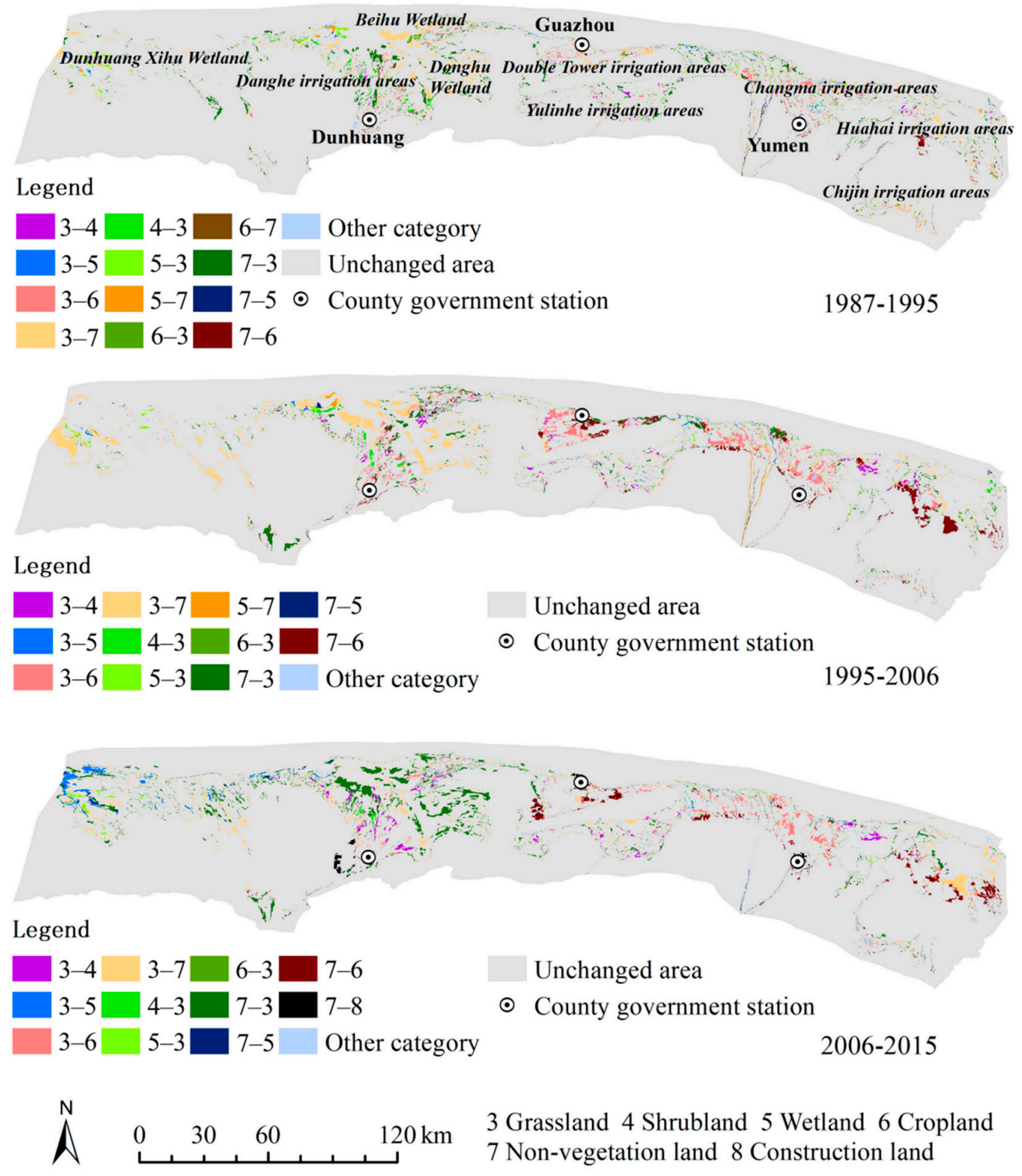

Figure 7. Spatial distribution map of different land types in the middle and lower reaches of the Shule River from 1987 to 2015.

Table 3 shows that during the period from 1987 to 1995, the LUCC in the study area mainly showed the conversion of grassland and non-vegetation area and the conversion of grassland to cultivated land. The change areas were mainly concentrated in Changma and Shuangta irrigation areas, Donghu Lake and Beihu Wetland. The main conversion types of 1995 2006 and 2006 2015 were similar. In addition to the above three types of conversion, the grassland turned to shrubland and the non-vegetation area turned to cultivated land. The change area is widely distributed, including in the Huahai Irrigation District, Changma Irrigation District and Double. Tower Irrigation District, North Lake and East Lake Wetland, West Lake Wetland and so forth. 
Table 3. Areas of main land conversion between different periods in the middle and lower reaches of the Shule River $\left(\mathrm{km}^{2}\right)$.

\begin{tabular}{cccc}
\hline Main Conversion Types & 1987 1995 & 1995 2006 & 2006 2015 \\
\hline Grassland $\rightarrow$ Shrubland & 45.63 & 97.75 & 128.42 \\
Grassland $\rightarrow$ Wetland & 43.10 & 37.91 & 125.80 \\
Grassland $\rightarrow$ Cropland & 142.41 & 372.62 & 212.98 \\
Grassland $\rightarrow$ Non-Vegetation & 427.22 & 694.10 & 378.59 \\
Shrubland $\rightarrow$ Grassland & 58.89 & 63.04 & 37.42 \\
Wetland $\rightarrow$ Grassland & 95.50 & 68.57 & 55.72 \\
Wetland $\rightarrow$ Non-Vegetation & 34.90 & 50.28 & - \\
Cropland $\rightarrow$ Grassland & 58.54 & 25.52 & 25.29 \\
Cropland $\rightarrow$ Non-Vegetation & 28.64 & - & - \\
Non-Vegetation $\rightarrow$ Grassland & 335.87 & 294.69 & 631.72 \\
Non-Vegetation $\rightarrow$ Wetland & 25.82 & 26.86 & 40.56 \\
Non-Vegetation $\rightarrow$ Cropland & 51.27 & 270.70 & 212.58 \\
Non-Vegetation $\rightarrow$ Construction Land & - & - & 53.91 \\
Other Land-Use Land-Cover Types & 52.77 & 123.95 & 112.50 \\
No change & 28696.43 & 27971.01 & 28081.48 \\
\hline
\end{tabular}

The spatial distribution of different land use/cover type changes has the following characteristics (Figure 7). The increased area of cultivated land is basically distributed around the resettlement site (expanded expansion) and the grassland inside the oasis (internal filling expansion). The change areas of grassland are widely distributed and the relatively concentrated areas are mainly distributed around the farming area, Donghu Lake, Beihu Lake and West Lake Wetland. The expansion of construction land is concentrated in Shazhou Town of Dunhuang and Qili Town, Guazhou County and Northern Industrial Logistics Park and around Yumen Town. The changing areas of the wetlands are mainly distributed along the Shule River and the Dunhuang North Lake and the West Lake Wetland. The changing areas of shrubland are mainly concentrated in the northern part of the Danghe Irrigation District, the Xihu Village in Guazhou County, the Qingshan Farm, the Ganhaizi Nature Reserve, the Changma Alluvial Fanling Zone in the Lockyang City and the protective forest area outside the farmland. The areas with non-vegetation area are widely distributed and the relatively concentrated areas are distributed around resettlement sites and the Dunhuang Beihu Wetland, East Lake Wetland and West Lake Wetland.

\section{Conclusions and Prospects}

This paper selects the middle and lower reaches of the Shule River as the research object, uses the Landsat remote sensing imagery from 1987, 1995, 2000, 2006, 2010, 2015 as the data source and performs manual visual interpretation in 8 major land types. The strength analysis method and the land use conversion intensity index are used to analyze the results and they revealed the temporal and spatial characteristics of land use/cover change in the study area over the past 30 years. The main conclusions are as follows:

(1) Between 1987 and 2015, the area of artificial vegetation (cultivated land) in the middle and lower reaches of the Shule River continued to increase and the total area of natural vegetation (grassland, shrubland and wetland) decreased by $917.69 \mathrm{~km}^{2}$, which represented a decrease of $-15.65 \%$. The area of cultivated land, construction land and shrubland increased by $95.12 \%, 220.99 \%$ and $49.35 \%$, respectively. The area of grassland, wetland and non-vegetation area decreased and high-, medium- and low-coverage grassland also decreased by $-2.19 \%,-21.26 \%$ and $-20.34 \%$, respectively. The decrease of wetland and non-vegetation area was -12.27 . $\%$ and $-1.41 \%$.

(2) The interval analysis shows that land use changes were faster during 2000 2006 and 2006 2010 and slower in other periods. According to the analysis of land-level hierarchy, the conversion intensity of medium- and high-coverage grassland was the highest, followed by low-coverage grassland, shrubland, wetland and construction land and cultivated land and the change of non-vegetation area was the smallest. Between 1987 and 2015, except for cultivated land, the pattern of land use 
change in the Shule River Basin did not change fundamentally and the overall situation was stable. The conversion analytic analysis showed that the main source of increased cultivated land was low-, medium- and high-coverage grassland and shrubland and the main transfer object was construction land. The main source of low-coverage grassland was medium- and high-coverage grassland and wetland. The main transfer objects were medium- and high-coverage grassland, shrubland and cultivated land. The main sources of transfer and transfer of medium-coverage grassland were high and low-coverage grassland and shrubland. The main sources of transfer and high-coverage grassland were medium-coverage grassland, shrubland and wetland. shrubland and wetlands were transferred to and from high-, medium- and low-coverage grasslands. The source of the non-vegetation area was low-coverage grassland and water-wet wetland and the target was low-coverage grassland. The main source of construction land was cultivated land.

(3) Between 1987 and 2015, the LUCC in the middle and lower reaches of the Shule River was severe at a change rate of $38.18 \%$ and a medium-to-high conversion ratio of more than $10 \%$ and it was most severe in the periods from 2000 to 2006 and 2006 to 2010. For the spatial distribution, the old farming areas in the oasis have changed little. The conversion areas were mainly concentrated around the oasis, natural vegetation coverage areas and resettlement sites, especially the Dunhuang Beihu Wetland, the East Lake Wetland and the West Lake Wetland. The increase in cultivated land was mainly around the resettlement site and the grassland inside the oasis. Grassland changes were widely distributed and the relatively concentrated areas were mainly around the farming area, Donghu Lake, Beihu Lake and West Lake Wetland. The expansion of construction land was mainly in Shazhou Town of Dunhuang and Qili Town, Guazhou County and North Industrial Logistics Park and Yumen Town. The change of wetlands was concentrated along the Shule River and the Dunhuang North Lake and the West Lake Wetland. The changes of shrubland were mainly distributed in the northern part of Danghe Irrigation District, West Lake Village in Guazhou and Qingshan Farm, Ganhaizi Nature Reserve, Lockyang City Area and farmland protection forest area. Wide variations in non-vegetation areas occurred and the relatively concentrated areas were distributed around the resettlement sites, Dunhuang Beihu Wetland, East Lake Wetland and West Lake Wetland.

The Shule River Basin is located in the westernmost part of the Hexi Corridor. Due to natural conditions, its resource carrying capacity is lower than that of the Shiyang River and Heihe River. However, due to the relatively low population density, few ecological problems are observed. After the founding of New China, the state has gradually increased the development of water and soil resources in the region. A number of farmland water conservancy facilities, such as Shuangta Reservoir, Danghe Reservoir and Changma Reservoir, have been built successively. The surface runoff process in the basin has been basically controlled by humans. Especially since the 1980s, the Gansu provincial government has successively transported more than 100,000 ecological immigrants to the region, which led to the addition of hundreds of thousands of acres of cultivated land and consumption of a large amount of ecological water, thus causing the shrinkage of natural vegetation. The research period covers the pre-, middle- and post-production of large-scale agricultural development in the Shule River Basin and considerable differences are observed before and after land use change. The results of this paper also show that during the implementation period of the agricultural irrigation and immigrant development agricultural irrigation project in the Shule River Basin (1996-2006), which was the most significant period of land use change in the basin, the spatial distribution was mainly concentrated on the edge of the oasis and resettlement sites. Along with the rapid expansion of cultivated land area, the net reduction of natural vegetation area, especially in the Dunhuang River downstream of Dunhuang, wetland shrinkage and vegetation degradation were more serious [47]. This phenomenon was most evident in the 1990s, which was due to large-scale agricultural development activities and the warm and dry climate conditions. Since the 21st century, the climate has changed from warm and dry to warm and humid and the precipitation and upstream runoff have gradually increased [48]. In recent years, the state has attached importance to local ecological protection, especially the rational use of Dunhuang water resources. Since the implementation of the Comprehensive Ecological Protection 
Plan (2011-2020), the annual transfer of water from the Danghe Reservoir and the Shuangta Reservoir to Dunhuang has been maintained at approximately $2 \times 108 \mathrm{~m}^{3}$ and the shrinkage of the North Lake and West Lake wetlands in Dunhuang has been reduced to some extent. Containment and vegetation restoration have occurred in local areas [49]. The results of this paper also show that the wetland and grassland area in Dunhuang City increased rapidly from 2010 to 2015. Due to space limitations, this paper did not analyze the abovementioned driving mechanism of land use change in detail and this aspect will be a focus of follow-up work.

The strength analysis method makes up for the shortcomings of the traditional LUCC analysis method that only pays attention to the absolute quantity of change and ignores the relative quantity of change. The comprehensive consideration of the duration of land use change, the absolute quantity of conversion and the scale factor of the transferred land type itself Answered "Which period of time when the LUCC is faster or slower," "Which land type changes are active or stable in each time period" and "what is the main transfer and transfer object of each class at different time periods." It can avoid the lack of dynamic dynamics of land change caused by the large area base. It can more accurately identify the hot land types of regional land use change and can identify the change of land change pattern of different land types at different time periods. Help us to gain a deeper insight into the laws of regional land change and provide reference for basin land control policies.

Author Contributions: F.D. and X.C. designed the study. F.D. wrote the main manuscript text, analyzed the data; X.C. supervised the manuscript and suggested revisions; J.Q. collected the data and drew the figures. All authors read and approved the final manuscript.

Funding: The paper is supported by the National Key R\&D Program of China (2018YFC0704700, 2018YFC0704702), the National Natural Science Foundation of China (41471462), the Fundamental Research Funds for the Central Universities (lzujbky-2016-241, lzujbky-2017-42, 18LZUJBWTD016) and the Soft Science Project of the Gansu Science and Technology Department (18CX1ZA042).

Conflicts of Interest: The authors declare no conflict of interest.

\section{References}

1. Meyer, W.B.; Turner, B.L. Human-Population Growth and Global Land-Use Cover Change. Annu. Rev. Ecol. Syst. 1992, 23, 39-61. [CrossRef]

2. Lambin, E.F.; Geist, H.J.; Lepers, E. Dynamics of land-use and land-cover change in tropical regions. Annu. Rev. Environ. Resour. 2003, 28, 205-241. [CrossRef]

3. Braimoh, A.K.; Osaki, M. Land-use change and environmental sustainability. Sustain. Sci. 2010, 5, 5-7. [CrossRef]

4. Chen, X.-L.; Zhao, H.-M.; Li, P.-X.; Yin, Z.-Y. Remote sensing image-based analysis of the relationship between urban heat island and land use/cover changes. Remote Sens. Environ. 2006, 104, 133-146. [CrossRef]

5. Roccati, A.; Luino, F.; Turconi, L.; Piana, P.; Watkins, C.; Faccini, F. Historical Geomorphological Research of a Ligurian Coastal Floodplain (Italy) and Its Value for Management of Flood Risk and Environmental Sustainability. Sustainability 2018, 10, 3727. [CrossRef]

6. Lazaro, R.; Rodrigo, F.S.; Gutierrez, L.; Domingo, F.; Puigdefabregas, J. Analysis of a 30-year rainfall record (1967-1997) in semi-arid SE Spain for implications on vegetation. J. Arid Environ. 2001, 48, 373-395. [CrossRef]

7. Xie, C.W.; Feng, J.M.; Wang, T. Land desertification in the source region of the Yellow River, northeast Qinghai-Xizang Plateau. Int. Geosci. Remote Sens. 2006, 1527-1532. [CrossRef]

8. Reynolds, J.F.; Smith, D.M.; Lambin, E.F.; Turner, B.L.; Mortimore, M.; Batterbury, S.P.; Downing, T.E.; Dowlatabadi, H.; Fernández, R.J.; Herrick, J.E.; et al. Global desertification: Building a science for dryland development. Science 2007, 316, 847-851. [CrossRef] [PubMed]

9. Brink, A.B.; Eva, H.D. Monitoring 25 years of land cover change dynamics in Africa: A sample based remote sensing approach. Appl. Geogr. 2009, 29, 501-512. [CrossRef]

10. Chen, X.; Bai, J.; Li, X.; Luo, G.; Li, J.; Li, B.L. Changes in land use/land cover and ecosystem services in Central Asia during 1990-2009. Curr. Opin. Environ. Sustain. 2013, 5, 116-127. [CrossRef]

11. Zhang, Y.S.; Li, X.Y.; Wang, L.X.; Zhang, H.Q. Impact of environmental factor variation on desertification: an example from the Shule River Area. P. Soc. Photo-Opt. Ins. 2003, 4890, 205-210. 
12. Song, X.; Yan, C.Z.; Li, S.; Xie, J.L. Assessment of sandy desertification trends in the Shule River Basin from 1978 to 2010. Sci. Cold Arid Reg. 2014, 16, 52-58.

13. Fensholt, R.; Langanke, T.; Rasmussen, K.; Reenberg, A.; Prince, S.D.; Tucker, C.; Scholes, R.J.; Le, Q.B.; Bondeau, A.; Eastman, R.; et al. Greenness in semi-arid areas across the globe 1981-2007-An Earth Observing Satellite based analysis of trends and drivers. Remote Sens. Environ. 2012, 121, 144-158. [CrossRef]

14. Xiao, J.; Moody, A. Geographical distribution of global greening trends and their climatic correlates: 1982-1998. Int. J. Remote Sens. 2008, 26, 2371-2390. [CrossRef]

15. Huang, J., Jr.; Pontius, R.G.; Li, Q.; Zhang, Y. Use of intensity analysis to link patterns with processes of land change from 1986 to 2007 in a coastal watershed of southeast China. Appl. Geogr. 2012, 34, 371-384. [CrossRef]

16. Ming, Y.; Chen, D.W.; Huang, R.H.; Ai, T.H. A Dynamic Analysis of regional Land Use and Cover Changing (LUCC) by remote sensing and GIS -Taking Fuzhou Area as example. Adv. Environ. Chem. Biol. Sens. Technol. VII 2010, 7673. [CrossRef]

17. Guo, H.; Xin, X.B. LUCC in Mentougou District Based on Remote Sensing and Transition Matrix. Proceedings of The 4th International Conference on Energy and Environmental Protection (Iceep 2015) 2015, Shenzhen, China, 2-4 June 2015; pp. 3450-3453. Available online: http://apps.webofknowledge.com/full_record. do?product=UA\&search_mode=GeneralSearch\&qid=6\&SID=5ETcIJGMgRvQxjDHcSE\&page=1\&doc=1 (accessed on 30 November 2019).

18. Takada, T.; Miyamoto, A.; Hasegawa, S.F. Derivation of a yearly transition probability matrix for land-use dynamics and its applications. Landsc. Ecol. 2010, 25, 561-572. [CrossRef]

19. Song, K.Y.; Zhao, J.Y.; Ouyang, W.; Zhang, X.; Hao, F.H. LUCC and landscape pattern variation of wetlands in warm-rainy Southern China over two decades. Procedia Environ. Sci. 2010, 2, 1296-1306. [CrossRef]

20. Zhang, F.; Yushanjiang, A.; Wang, D. Ecological risk assessment due to land use/cover changes (LUCC) in Jinghe County, Xinjiang, China from 1990 to 2014 based on landscape patterns and spatial statistics. Environ. Earth Sci. 2018, 77, 491. [CrossRef]

21. Jenerette, G.D.; Wu, J.G. Analysis and simulation of land-use change in the central Arizona-Phoenix region, USA. Landsc. Ecol. 2001, 16, 611-626. [CrossRef]

22. Aldwaik, S.Z.; Pontius, R.G. Intensity analysis to unify measurements of size and stationarity of land changes by interval, category, and transition. Landsc. Urban Plan. 2012, 106, 103-114. [CrossRef]

23. Alo, C.A.; Pontius, R.G. Identifying Systematic Land-Cover Transitions Using Remote Sensing and GIS: The Fate of Forests inside and outside Protected Areas of Southwestern Ghana. Environ. Plan. B Plan. Des. 2008, 35, 280-295. [CrossRef]

24. Pontius, R.G.; Malizia, N.R. Effect of Category Aggregation on Map Comparison. Geogr. Inf. Sci. 2004, 3234, 251-268.

25. Pontius, R.G.; Gao, Y.; Giner, N.M.; Kohyama, T.; Osaki, M.; Hirose, K. Design and Interpretation of Intensity Analysis Illustrated by Land Change in Central Kalimantan, Indonesia. Land 2013, 2, 351-369. [CrossRef]

26. Akinyemi, F.O.; Pontius, R.G.; Braimoh, A.K. Land change dynamics: Insights from Intensity Analysis applied to an African emerging city. J. Spat. Sci. 2016, 62, 1-15. [CrossRef]

27. Teixeira, Z.; Marques, J.O.C.; Pontius, R.G. Evidence for deviations from uniform changes in a Portuguese watershed illustrated by CORINE maps: An Intensity Analysis approach. Ecol. Indic. 2016, 66, 382-390. [CrossRef]

28. Hasani, M.; Sakieh, Y.; Dezhkam, S.; Ardakani, T.; Salmanmahiny, A. Environmental monitoring and assessment of landscape dynamics in southern coast of the Caspian Sea through intensity analysis and imprecise land-use data. Environ. Monit. Assess. 2017, 189, 163. [CrossRef] [PubMed]

29. Yang, Y.; Liu, Y.; Xu, D.; Zhang, S. Use of intensity analysis to measure land use changes from 1932 to 2005 in Zhenlai County, Northeast China. Chin. Geogr. Sci. 2017, 27, 441-455. [CrossRef]

30. Huang, B.; Huang, J.; Pontius, R.J., Jr.; Tu, Z. Comparison of Intensity Analysis and the land use dynamic degrees to measure land changes outside versus inside the coastal zone of Longhai, China. Ecol. Indic. 2018, 89, 336-347. [CrossRef]

31. Wei, W.; Zhao, J.; Wang, X.-F. Landscape heterogeneity of land use types in Shiyang River basin. Chin. J. Ecol. 2010, 29, 760-765.

32. Wang, Z.; Ficklin, D.L.; Zhang, Y.; Zhang, M. Impact of climate change on streamflow in the arid Shiyang River Basin of northwest China. Hydrol. Process. 2012, 26, 2733-2744. [CrossRef] 
33. Huo, Z.; Feng, S.; Kang, S.; Li, W.; Chen, S. Effect of climate changes and water-related human activities on annual stream flows of the Shiyang river basin in and north-west China. Hydrol. Process. 2008, 22, 3155-3167. [CrossRef]

34. Nian, Y.; Li, X.; Zhou, J.; Hu, X. Impact of land use change on water resource allocation in the middle reaches of the Heihe River Basin in northwestern China. J. Arid Land 2014, 6, 273-286. [CrossRef]

35. Ma, M.; Frank, V. Interannual variability of vegetation cover in the Chinese Heihe river basin and its relation to meteorological parameters. Int. J. Remote Sens. 2006, 27, 3473-3486. [CrossRef]

36. Wang, G.; Liu, J.; Kubota, J.; Chen, L. Effects of land-use changes on hydrological processes in the middle basin of the Heihe River, northwest China. Hydrol. Process. 2007, 21, 1370-1382. [CrossRef]

37. Lu, L.; Li, X.; Cheng, G.D. Landscape evolution in the middle Heihe River Basin of north-west China during the last decade. J. Arid Environ. 2003, 53, 395-408. [CrossRef]

38. Chen, S.; Liu, W.; Qin, X.; Liu, Y.; Zhang, T.; Chen, K.; Hu, F.; Ren, J.; Qin, D. Response characteristics of vegetation and soil environment to permafrost degradation in the upstream regions of the Shule River Basin. Environ. Res. Lett. 2012, 7, 0454064. [CrossRef]

39. Qi, J.; Niu, S.; Zhao, Y.; Liang, M.; Ma, L.; Ding, Y. Responses of Vegetation Growth to Climatic Factors in Shule River Basin in Northwest China: A Panel Analysis. Sustainability 2017, 9, 368. [CrossRef]

40. Qi, J.-H.; Niu, S.-W.; Ma, L.-B.; Wang, W.-D. The characteristics and driving forces of LUCC in the middle and lower reaches of Shule River Basin. Chin. J. Ecol. 2014, 33, 2207-2220.

41. USGS. Available online: https:/ /glovis.usgs.gov / (accessed on 20 March 2017).

42. Institute of Remote Sensing and Digital Earth Chinese Academy of Sciences. Available online: http:/ / www. ceode.cas.cn/sjyhfw/ (accessed on 22 March 2017).

43. Resource and Environment Data Cloud Platform. Available online: http://www.resdc.cn/ (accessed on 25 March 2017).

44. Cold and Arid Region Science Data Centre. Available online: http://westdc.westgis.ac.cn/ (accessed on 28 March 2017).

45. National Earth System Science Data Sharing Platform. Available online: http://www.geodata.cn/ (accessed on 30 March 2017).

46. Janssen, L.L.F.; Vanderwel, F.J.M. Accuracy Assessment of Satellite-Derived Land-Cover Data-A Review. Photogramm. Eng. Remote Sens. 1994, 60, 419-426.

47. Yin, D.; Li, X.; Huang, Y.; Si, Y.; Wei, J.; Liu, J.; Bai, R. Ecosystem stability analysis with LUDC model and transitional area ratio index for Xihu oasis in Dunhuang, China. Environ. Earth Sci. 2016, 75, 707. [CrossRef]

48. Shi, Y.; Shen, Y.; Kang, E.; Li, D.; Ding, Y.; Zhang, G.; Hu, R. Recent and future climate change in northwest china. Clim. Chang. 2007, 80, 379-393. [CrossRef]

49. Pan, F.; Xie, J.; Lin, J.; Zhao, T.; Ji, Y.; Hu, Q.; Pan, X.; Wang, C.; Xi, X. Evaluation of Climate Change Impacts on Wetland Vegetation in the Dunhuang Yangguan National Nature Reserve in Northwest China Using Landsat Derived NDVI. Remote Sens. 2018, 10, 735. [CrossRef]

(C) 2019 by the authors. Licensee MDPI, Basel, Switzerland. This article is an open access article distributed under the terms and conditions of the Creative Commons Attribution (CC BY) license (http:// creativecommons.org/licenses/by/4.0/). 